\title{
Energy Efficiency Increase in a Chemical Production Site
}

\author{
Urs Keller* and Walter Jucker
}

\begin{abstract}
Sustainability has become a key factor for the chemical industry. One element of sustainability is energy efficiency in manufacturing processes. This article illustrates the strategic energy initiatives of a leading global operating company and the implementation of its elements into practice. Some successful energy-saving projects are highlighted.
\end{abstract}

Keywords: Biofouling · Eco efficiency $\cdot$ Energy saving projects $\cdot$ Responsible care program $\cdot$ Sustainability

\section{Introduction}

The chemical industry is not an energy-intensive industry but consumes large amounts of energy, especially for steam production. Twenty years ago as a commitment for the UNCED conference in Rio de Janeiro, the chemical industry started their sustainability initiative Responsible Care. ${ }^{[1]}$ The Swiss chemical industry started its own local program in 1991.

In a manufacturing site energy costs are typically ranked as the number four cost category of the added value costs after personnel costs, depreciations and raw material. The high impact of energy costs facilitated the acceptance of eco efficiency in the chemical industry. A search on homepages of chemical industries showed that 'energy efficiency' is embedded in all business strategies of relevant players. The Swiss chemical industry forms one of the 'energy model groups' in the initiative of 'Energieagentur der Wirtschaft'. As one of the most successful groups it has achieved beyond its targets. This paper presents the strategy and success stories for energy efficiency increase at the DSM site Sisseln. The core content was presented at the $10^{\text {th }}$ Freiburger Symposium in 2011.[2]

\section{Energy Initiatives of DSM Nutritional Products Ltd.}

For many years DSM has ranked in the top performer group of the Chemical Industry Sector in the Dow Jones Sustainability Index (DJSI). It was number one in five out of the past seven years. The impressive successes are only possible when sustainability is a top priority for the company. In line with corporate strategy DSM Nutritional Products Ltd. (DNP) started its energy initiative 2006 to 2010. The goal was to reduce the energy consumption by $10 \%$ based on a comparable production output. For the site Sisseln this represented a reduction of 37'000 MWh per year despite the fact that 'low hanging fruit' had already been harvested at the end of the nineties. The work was started with a classical project approach with the business group energy manager as program director. He was supported by the site energy managers forming the energy manager team. This team met two times a year to exchange best practices and challenge the presented ideas. Finally the site energy managers relied on local energy teams formed by experienced technical supervisors. Like in other management initiatives transparency and key performance indicator (KPI) definitions are the key for success. On the site a metering concept was implemented. It encompassed delivery meters, main meters and allocation meters (Fig. 1). To meet an 80/20 approach 30 delivery meters and 320 consumption meters were necessary. The consumption meters were roughly 50:50 electronic:manual. Eight production plants, boiler house, utilities units (brine, cooling water and compressed air) and the wastewater treatment plant were equipped. Warehouses, laboratories and administration building were not included. For each measured plant production volumes, steam consumption and electricity consumption were monitored on a monthly basis. The variances between delivered and used energies were determined to get an idea of losses. The monthly data were plotted and checked for linearity (Fig. 2). In case of bias from linearity the cause was investigated and eliminated. The data of the eleven consumers were condensed in the KPI 'energy performance indicator' (EPI). The EPI is the fraction between energy consumption and produced volumes. The KPI is compared with the mean of the
${ }^{*}$ Correspondence: U. Keller DSM Nutritional Products AG, Site Sisseln Energy Manager

Bau 320

Hauptstrasse 4

$\mathrm{CH}-4334$ Sisseln

Tel.: +4162866 2551

E-Mail: Urs.Keller@DSM.com

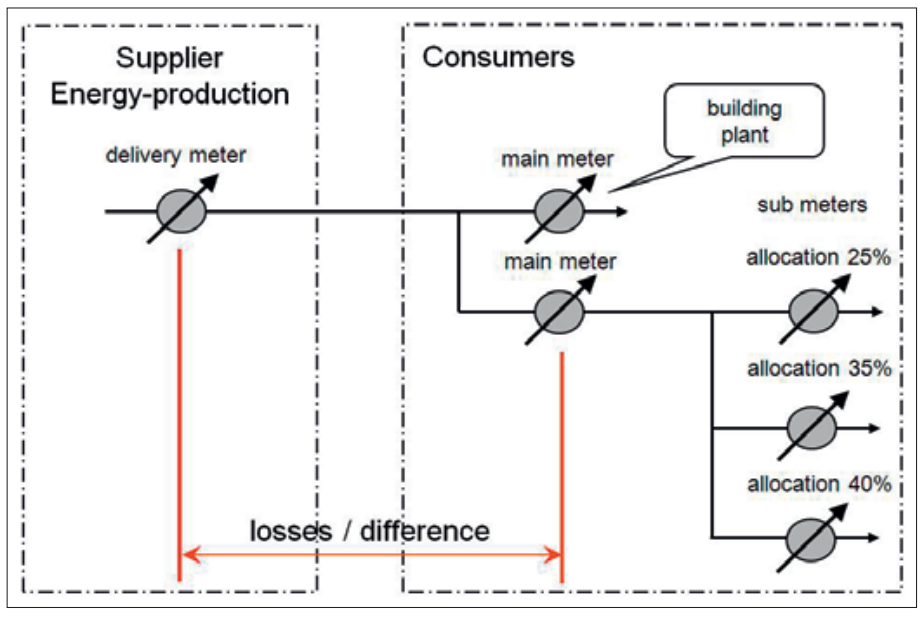

Fig. 1. The metering strategy benefits from the energy equilibrium. The sum of main meter consumptions on the consumer site plus a site-specific term for losses should represent the sum of delivery meters. Allocation meters break down the main meter consumption of a plant to individual equipment. 

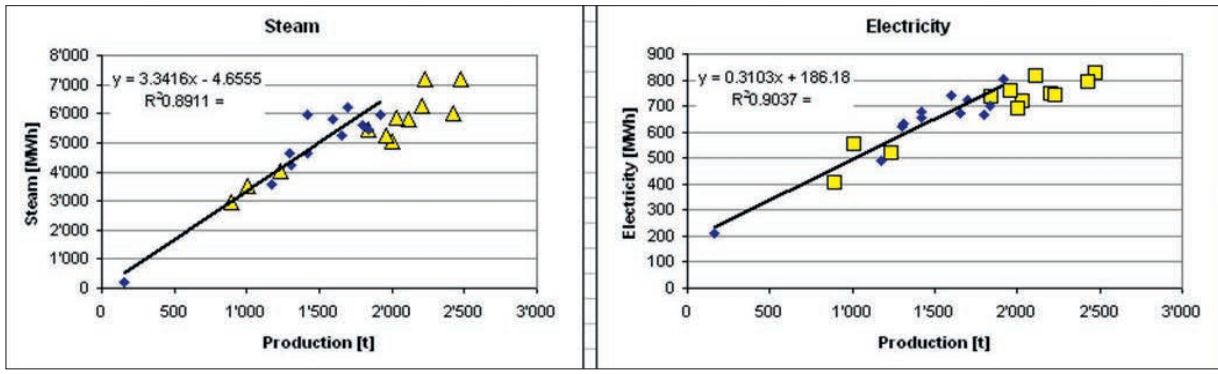

Fig. 2. Ideally energy consumption and production volumes result in a linear correlation. At maximum capacity holding times are at minimum and therefore a slight positive bias from linearity appears.

base year. A positive percentage means an increase of energy efficiency. Fig. 3 is an example of the management information package. It is clearly visible that the EPI is not a pure physical parameter. There are seasonal fluctuations with poorest figures in winter. Furthermore the product mix on multipurpose plants and start-up/shutdown processes will influence the KPI. Nevertheless the repetitive seasonality and the averaging all over the site and year result in a sound KPI. Fig. 4 proves that energy efficiency is not just dependent on

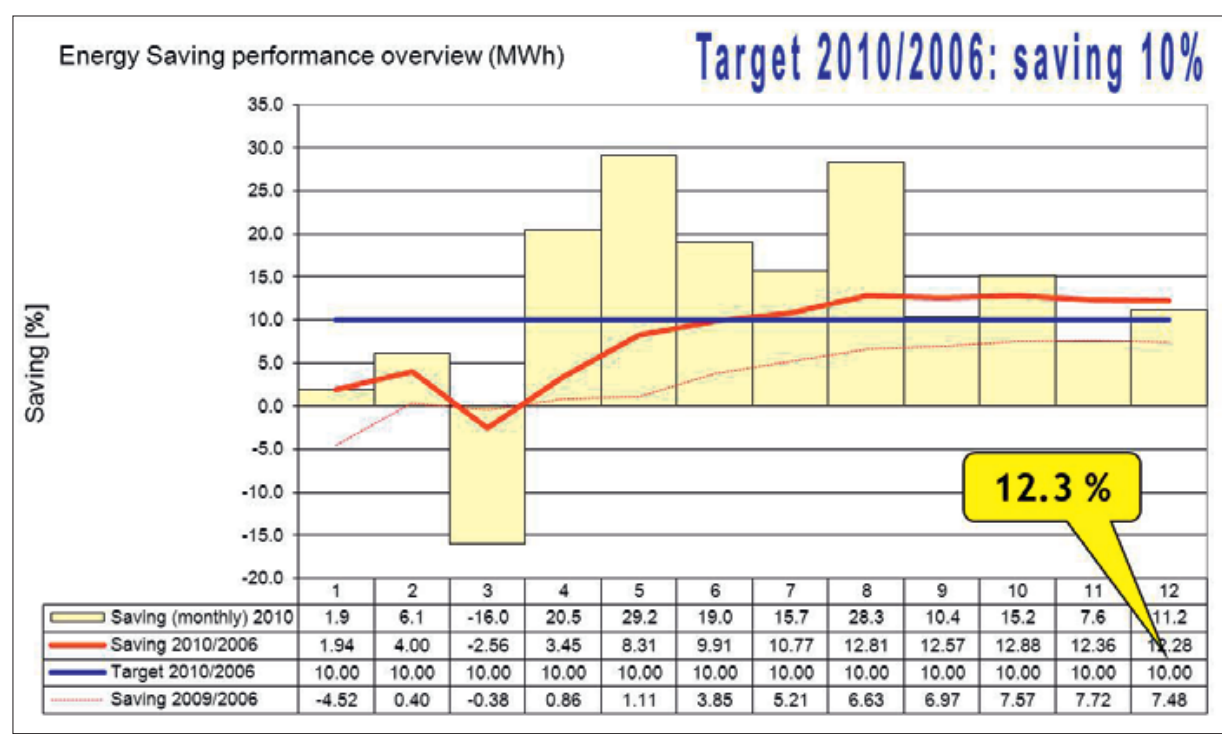

Fig. 3. The energy performance indicator (EPI) is a KPI for energy usage corrected for production volume fluctuations. The seasonality with low performance in cold months is striking. The peak in August reflects the total ejection of products before the shutdown period for maintenance work.

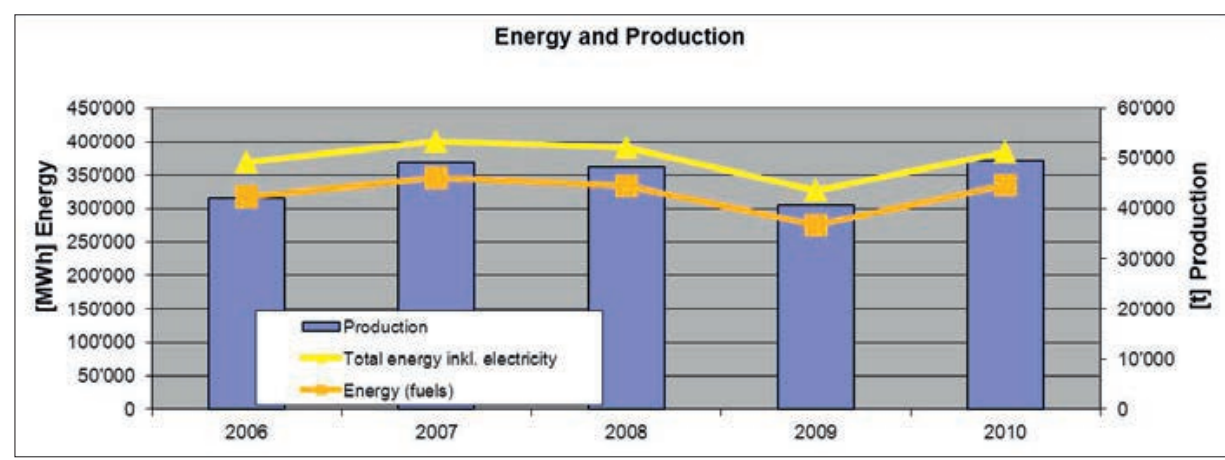

Fig. 4. Annual production volumes govern the energy consumption. Energy saving efforts between 2006 and 2009 are striking. tiative which resulted in less rework/reprocessing. The financial benefits of the initiative are calculated to $1.5 \mathrm{Mio} \mathrm{CHF}$ savings per year.

The Swiss chemical industry has reduced its $\mathrm{CO}_{2}$ emissions which are a good indicator for energy consumption in the same timespan by about the same percentage. ${ }^{[3]}$

In other words DNP site Sisseln plays an important role in sustainability but is not the only successful company. In the year 2009 DSM launched the new energy initiative 2008-2020. The target value for reduction of energy consumption is $-20 \%$ at comparable production volumes. The project set up is similar as described above. It is assumed that chemical process improvements, renewable energies and replacement of old less efficient equipment will play a more prominent role. It is an ambitious initiative but DSM will achieve for the benefit of environment and the company itself.

\section{Success Stories}

\subsection{Biofouling}

Biofouling means the build-up of microbiological films on the inner surface of pipes and equipment. These biofilms hamper the heat transmission in water-cooling heat exchanges. The less heat absorbed per cubic meter water, the more water is consumed. Since cooling water must be pumped from the river Rhine to the water tower, the water consumption is directly proportional to the energy consumption. The scope of an energy reduction project was therefore to destroy biofilms on the water side of equipment based on the oxidative power of $\mathrm{H}_{2} \mathrm{O}_{2}$.

Fig. 5 shows the general make-up of biofilms and the way of action of ' $\mathrm{Mol}^{\circledR}$ aktiv E30', a $\mathrm{H}_{2} \mathrm{O}_{2}$-based chemical product, the simple integration of the dosing station in the cooling water system (see Fig. 6) and the results of water consumption with and without anti-biofilm agent (Fig. 7). The effect is more prominent in the summer months when water temperatures are above $20^{\circ} \mathrm{C}$. The saving of electricity consumption is calculated with $500 \mathrm{MWh}$ per year which is $5 \%$ of the electricity used for water pumping.

\subsection{Replacement of the Aeration System in a Wastewater Treatment Plant}

Wastewater treatment plants (WWTP) on chemical production sites and the high salt load of the wastewater results in highly corrosive surroundings. Due to this corrosion damage the aeration system had to be replaced. The old system was composed of 'fungi-like' steel plates with no return 


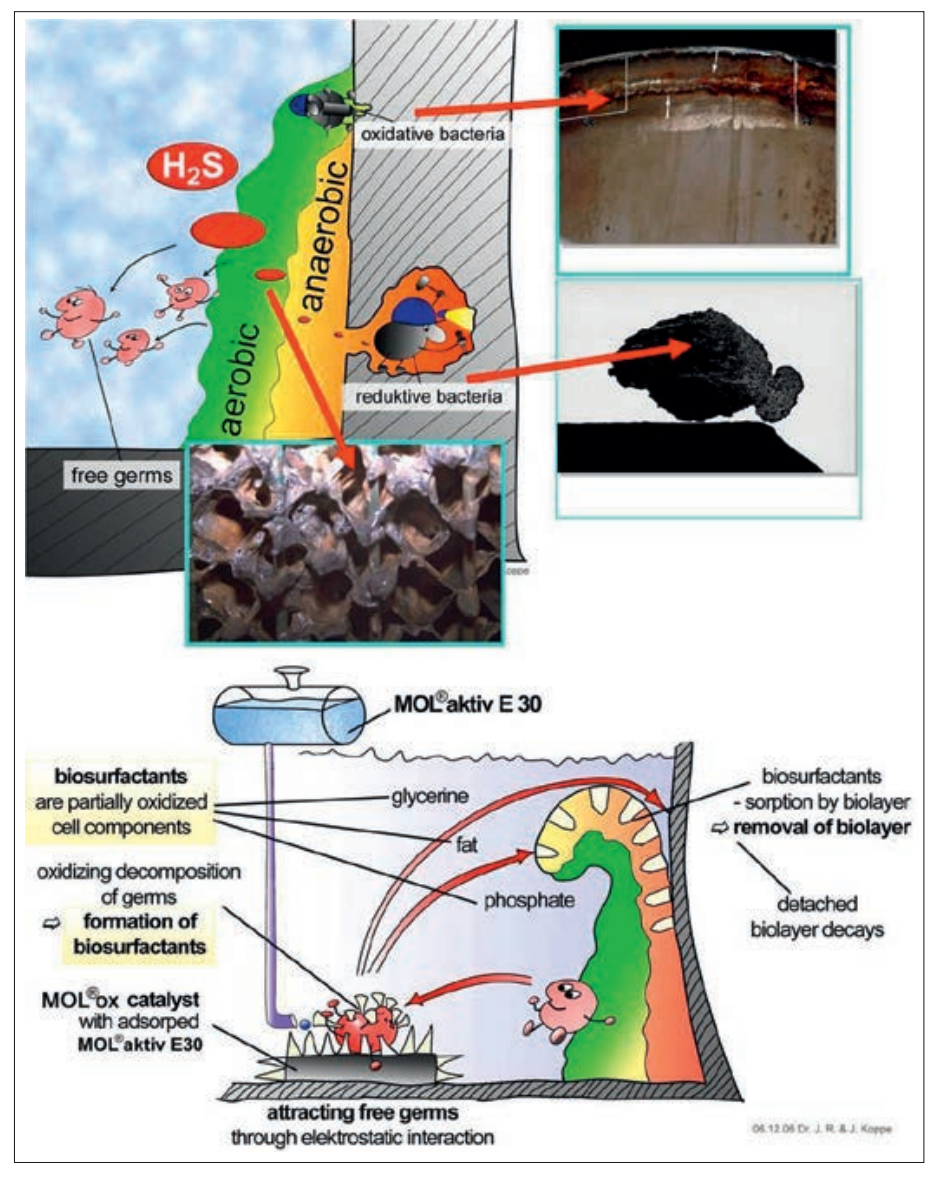

Fig. 5. The upper picture gives the general architecture of biofilms. On the water side of the biofilm, aerobic bacteria and in the deeper layers at the equipment side anaerobic bacteria live. Both types produce corrosive by-products. Below: The Molox catalyst attracts germs and degrades them by the oxidative power of $\mathrm{H}_{2} \mathrm{O}_{2}$. The biofilm is reduced layer by layer.

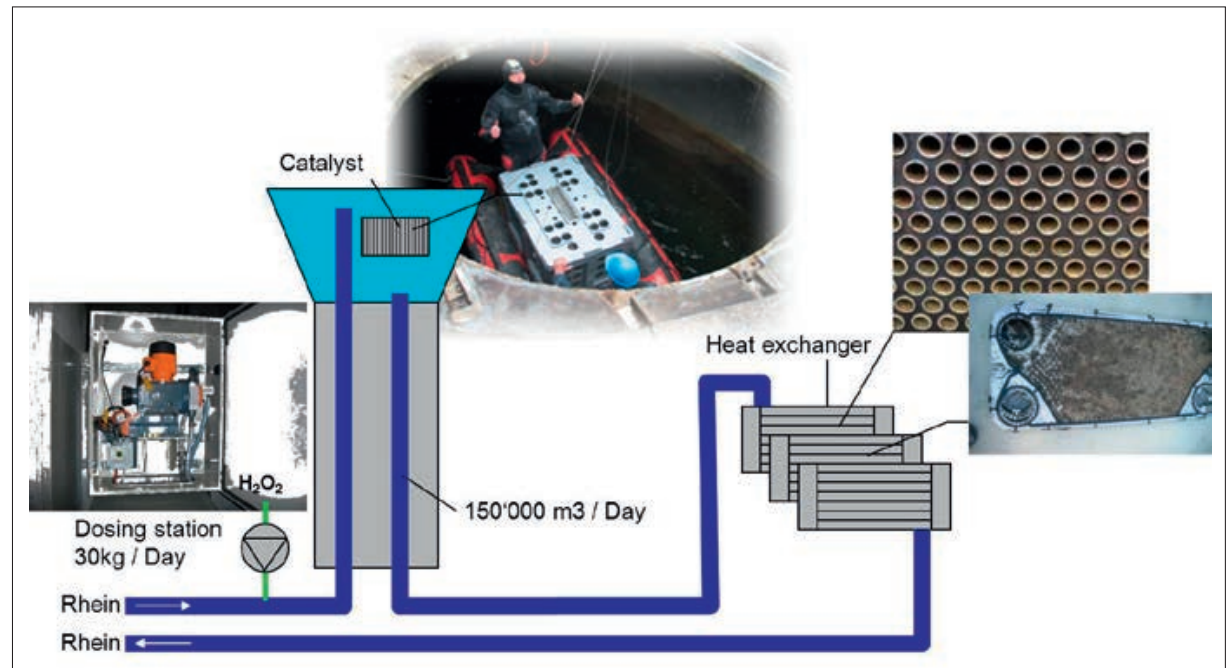

Fig. 6. Schematic diagram of the cooling water system of the site Sisseln is illustrated. Water is pumped from the river Rhine to the water tower. At the entry to the tower $\mathrm{H}_{2} \mathrm{O}_{2}$ is added in low concentrations. The catalyst unit is positioned in the reservoir of the water tower. From the tower the cooling water flows through the heat exchanger units and back to the Rhine. On the way through the equipment $\mathrm{H}_{2} \mathrm{O}_{2}$ is completely used.

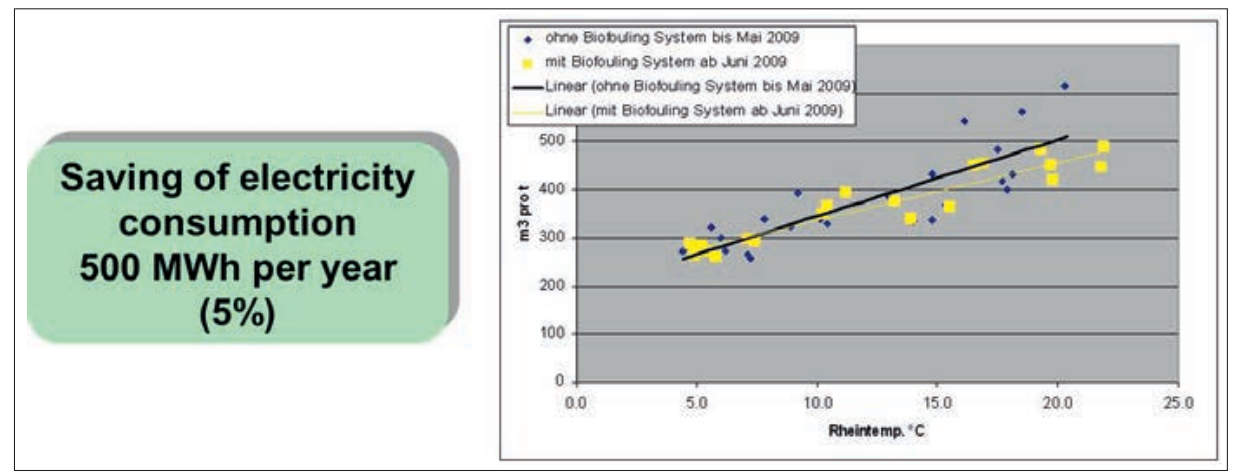

valves. Following an intensive market research a new system with membrane diffusers instead of a 1:1 replacement was chosen. The new system shows remarkably increased energy efficiency. The electricity consumption of the aeration system could be reduced by $265 \mathrm{MWh}$ per year or $11 \%$. Fig. 8a illustrates the old and Fig. $8 \mathrm{~b}$ the new aeration system.

\subsection{Online Balancing}

The steam production of the site is mainly done by two gas-heated boilers with capacities of 60 and 100 tonnes respectively. The overall steam production incl. delivery to third parties is about 500'000 tonnes a year. In 2008 an online balancing tool was installed in the control room. With this tool steam production, oxygen concentration in the incinerator and efficiency of energy use can be monitored simultaneously. By reading the line characteristics and corrective actions if warning limits are exceeded the control room operator has the possibility to adjust steam production to the actual need and in parallel to maximize the energy efficiency. Fig. 9a gives an example of the characteristics and visualizes the differences between 2008 (without balancing) and 2010 with balancing. The energy efficiency increase of $0.3 \%$ equals a saving of 30'000 Swiss francs per year (Fig. 9b).

\subsection{New Control System in a Production Plant}

In a mono-plant an old control system with a low automation degree and a lot of manual settings was in use. Based on the transparency on energy consumption by the metering equipment a $15 \%$ loss during shutdown periods was observed. Furthermore we expected additional energy losses caused by the functioning principle of the old valves. The replacement of instrumentation and control systems at the end of their lifetime by state-of-the-art equipment resulted in an impressive improvement. The steam consumption in the plant could be cut by $25 \%$ at comparable production volumes!

\subsection{Motor Replacement}

The energy efficiency of electrical motors has increased dramatically in the last years. Taking into account the energy efficiency in each and every motor replacement project is one of the simplest methods for saving energies. When calculating project costs it is of utmost importance to use the life time cost approach instead of just assessing the investment costs. Thanks to the long lifetime of motors the additional

Fig. 7. Plot of cooling water consumption depending on the temperature of Rhine water. The warmer the water temperature the more effective is the Molox system. 


\section{Old System}

- Installed in 1989

- Corrosion $\rightarrow 1.4301$ installed; necessary is 1.4404 or 1.4571

- No return valves $\rightarrow$ sludge-water flows into the pipe $\rightarrow$ corrosion
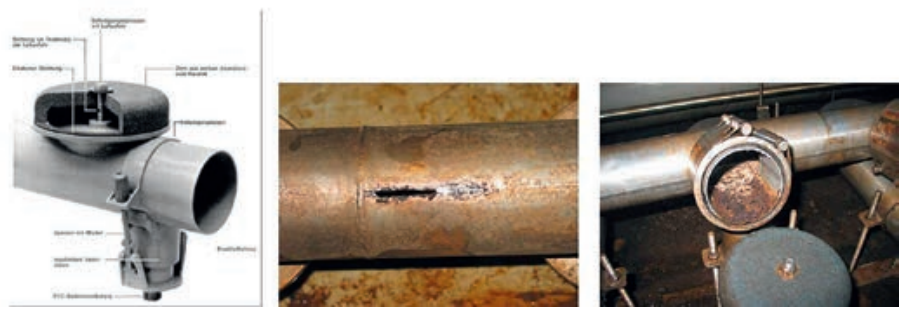

a)

\section{New System}

- Membrane diffuser

- Improved air distribution

- Less maintenance

- Reduced blower capacity

- Reduced electricity consumption

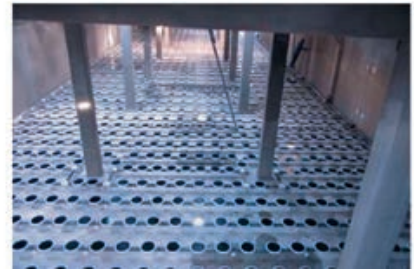

b)

Saving of electricity

consumption

265 MWh per year

$(11 \%)$

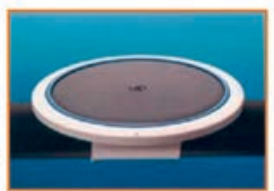

Fig. 8. a) Schematic diagram of the old, mechanical aeration system of the wastewater treatment plant. The two pictures demonstrate the corrosion damage in the piping system. b) The new aeration system is either of higher steel quality or of plastic material and therefore not susceptible to corrosion damage. The more effective air bubble production results in a reduced electricity consumption.

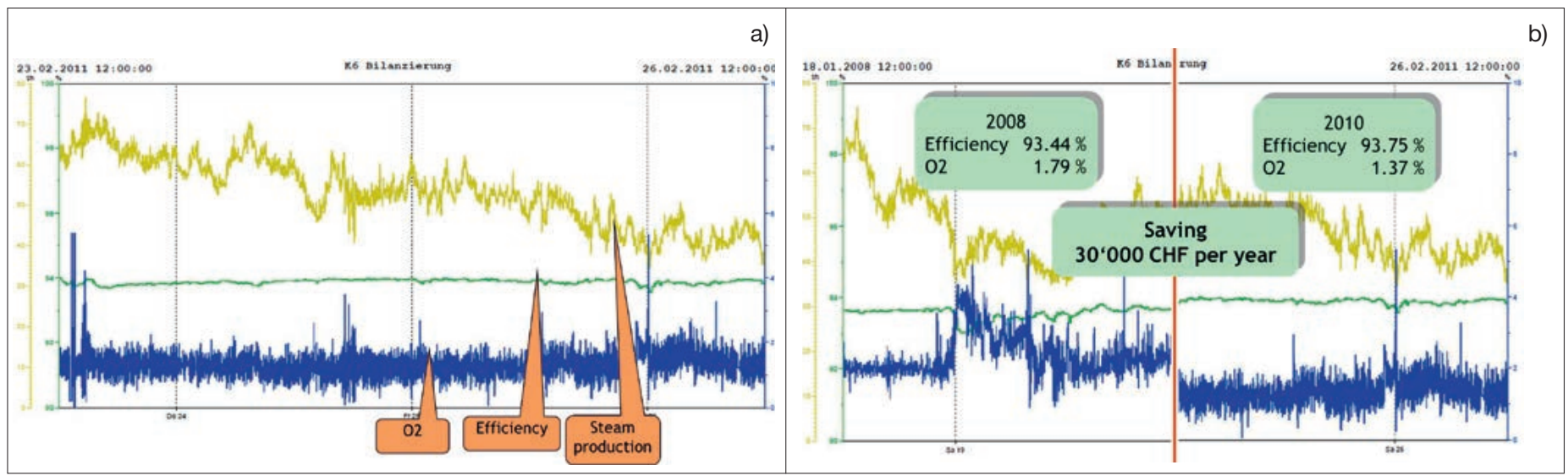

Fig. 9. a) Online balancing visualized in the control room. The oxygen content in the incinerator is decoupled from the steam production. b) Before online balancing (left) oxygen content in the incinerator increased when the steam consumption decreased. With online balancing the oxygen content is held on a constant low and effective level despite fluctuations in the steam demand.

\section{Old system}

- Flue gas ventilator motor $90 \mathrm{~kW}$ with swirl flap

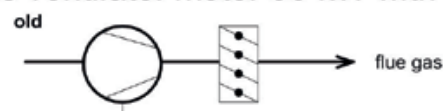

\section{New system}

(M)

- New motor $75 \mathrm{~kW}$ with IE2 efficiency factor and frequency speed control system

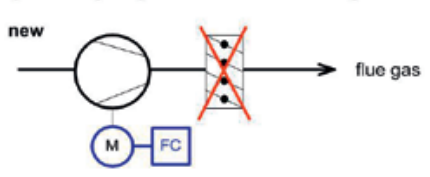

Saving of electricity consumption $70 \mathrm{MWh}$ per year $(5 \%)$
Fig. 10. Motor replacement in systems at their end of lifetime is a simple and effective measure to increase energy efficiency. investment costs for the most efficient motors pay out in the short- to midterm. Fig. 10 gives an example implemented on our site. Figs $11 \mathrm{a}$ and $11 \mathrm{~b}$ illustrate another example with big motors and consequently impressive energy savings in our boiler house.

\section{Discussion}

The total energy consumption for Switzerland reached in 2010 a near alltime high of 911,550 terajoule. The increase compared with 2009 was $4.4 \% .{ }^{[4]}$ This report demonstrates that prosperous

\section{Old system}

- Boiler feed water pump and fresh air ventilator motor

- 40 year old motors with a resistor speed control system

- All energy is used up over resistor a)

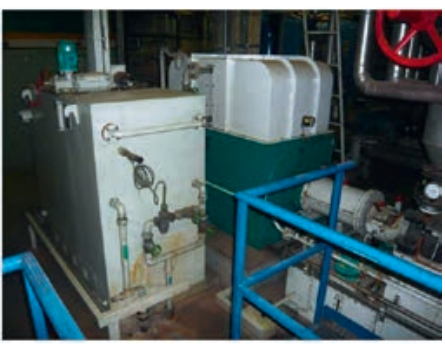

New system

- Two new motors with $96.5 \%$ efficiency factor and frequency speed control system

Saving of electricity consumption 1 '000 MWh per year $(20 \%)$ b)

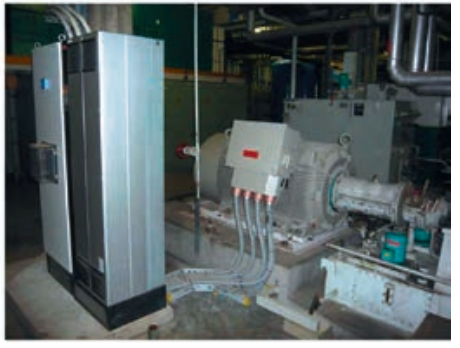

Fig. 11. a) Old feed water pump motor with resistor speed control system. b) New feed water pump motor with frequency speed control system. 
industrialized countries are a long way from decoupling their energy consumption from gross domestic product (GDP). The GDP of Switzerland increased only $2.6 \%$ from 2009 to 2010. The non-proportional increase is explained with more heating energy. The scale 'Heizgradtage' increased by $12.7 \%$. A second explanation is the growth in the Swiss population by $1 \%$. Furthermore the mobility needs of individuals are still increasing. The number of vehicles increased $1.6 \%$ more than the number of inhabitants. The mobility increase over-compensated the efficiency increases of modern car motors.

Compared with the whole country the energy efficiency increase of site Sisseln of DNP is more favorable. The energy consumption of the chemical manufacturing site represents about $0.15 \%$ of Swiss energy consumption. In Fig. 4 it can be seen that in 2010 the peak production level but not the peak energy consumption level was achieved. In other words Sisseln was able to break the linearity between production output and energy consumption. The success of Sisseln is in line with the chemical and pharmaceutical industries.

The sustainability reports of F. Hoffmann-La Roche Ltd. , ${ }^{[5]}$ Clariant ${ }^{[6]}$ and Syngenta ${ }^{[7]}$ show similar achievements at a corporate level.

Naturally such impressive results do not just happen. It needs a clear strategy, the commitment of management and an energy saving project with highly motivated project members. That is the ultimate key for success. This paper gives five examples of very successful and profitable projects. They are shared to stimulate energy saving ideas in other companies. The exchange of experiences is one of the success factors of the DSM project and a corner stone of the Responsible Care program. The homepage of 'Energieagentur der Wirtschaft' gives a helpful guideline how to start an energy initiative in a company. ${ }^{[8]}$ For steps 2, 3 and 4, a basic understanding of energy flows is essential. To get this information metering equipment is an absolute must. A possible strategy is given in Fig. 1. It is not necessary to start with a comprehensive system. Sub meters can be installed as a second priority when the main consumers are known. A too sophisticated metering system results in a high financial hurdle to start with. This is one of the most often heard killer criteria against energy saving projects. Less is more even in energy saving projects! It is also crucial to define minimal expectations for rates of return. Payback times for energy saving projects may be somewhat longer than for capacity increase projects but they should lie in an acceptable range. The presented projects of this paper have typical payback times of $<5$ years. Additional case studies can be found in literature, e.g. DeSimone and Popoff, chapters 3 and $6^{[9]}$ or Holliday et al., chapter 3. ${ }^{[10]}$

As mentioned in section 2 DSM has initiated the next generation of energy saving efforts. For the site Sisseln a new project plan was prepared. One of the most ex- pensive but also most promising projects is the installation of an additional electricity turbine to use the energy content of 36 bar steam produced by our waste incinerator. This will be the third electricity cogeneration unit on site. All three units together will allow site Sisseln to produce more than $50 \%$ of its electricity demand itself. This is an exciting start towards next step in energy efficiency increase.

Received: August 8, 2013

[1] International Council of Chemical Associations (ICCA) Responsible Care Initiative, www.iccachem.org

[2] O. Naef, Chimia 2012, 66, 248

[3] Scienceindustries, Switzerland, Nachhaltigkeitsbericht scienceindustries, Mai 2012

[4] Bundesamt für Energie BFE, Schweizerische Gesamtenergiestatistik 2010, 2012.

[5] F. Hoffmann-La Roche Ltd., www.roche.com/ corporate responsibility, 2012.

[6] Clariant www.clariant.com/Environment, Safety \& Health / Key performance Indicators, 2012.

[7] Syngenta, Annual Report 2011, Environment, Energy efficiency, 2012.

[8] Energieagentur der Wirtschaft, 'In 7 Schritten zur energiebewussten Geschäftsprozess- und Produktionsoptimierung', 2005, www.energieschweiz.ch

[9] L. D. DeSimone, F. Popoff, 'Eco Efficiency the Business Link to Sustainable Development', MIT press, Cambridge, 1998.

[10] C. O. Holliday, S. Schmidheiny, P. Watts, 'Walking the Talk', Greenleaf Publishing, Sheffield, 2002. 